\title{
Determinação da variaçâo no microclima de Manaus- AM por atividades antropogênicas e modulações climáticas naturais
}

\author{
Flavio Mendes OLIVEIRA ${ }^{1}$, Rutenio Luiz ARAÚJO², João Silva CARVALHO ${ }^{3}$, Solange Santos COSTA ${ }^{4}$
}

\begin{abstract}
RESUMO
O foco principal deste artigo foi detectar mudanças no microclima da cidade de Manaus (AM), Brasil e procurar indicar as possíveis causas destas flutuações e tendências observadas. A análise está baseada em informaçōes geotérmicas e meteorológicas. Por dados meteorológicos determinamos um incremento nas temperaturas médias do ar de $0,27 \pm 0,04^{\circ} \mathrm{C}$, durante os últimos 80 anos, baseado na normal climatológica de 1950 a 1979 e este incremento não tem sido contínuo, mas parece ser modulado pelas freqüências de meses com El Niño, La Niña e Neutros, detectados no Oceano Pacifico tropical. Contudo, por dados geotérmicos, nós determinamos um incremento quase instantâneo de $3,17^{\circ} \mathrm{C} \pm 0,53{ }^{\circ} \mathrm{C}$, relacionado com o uso do solo. Verificamos que as perturbaçôes transientes do subsolo de locais com cobertura vegetal são bons indicadores das variabilidades climáticas anuais recentes e que as análises dos perfis sob locais sem cobertura vegetal indicam mudanças no microclima atribuídas às atividades antrópicas, tais como, o desflorestamento e urbanização.
\end{abstract}

PALAVRAS-CHaVE: Mudanças Microclimáticas; Atividades Antrópicas; Variabilidades Naturais.

\section{Determination of variation in the Manaus-AM microclimate for anthropogenic activities and natural climatic modulations}

\section{ABSTRACT}

The focus of this paper was to detect microclimate changes in Manaus City (AM), Brazil in attempting to indicate possible causes for the fluctuations and trends observed. The analysis is based on Meteorological and shallow geothermal records. The meteorological data indicated an increment of $0.27 \pm 0.04{ }^{\circ} \mathrm{C}$ in the mean surface air temperature during the last 80 years with reference to the 1950-1979 climatological mean and this increment has not been continuous, but seem to be modulated by frequency of El Niño, La Niña e Neutral events over the tropical Pacific Ocean. Though, quasi-instantaneous increment of $3.17 \pm 0.53^{\circ} \mathrm{C}$ was determined from geothermal data, which is associated with the land-use changes. From shallow geothermic data under sites with vegetation cover we verified that transient perturbations are good indicators of recent annual climate variability, while analysis of temperature profiles data under sites without vegetation cover seem to indicate microclimate changes related to the anthropogenic actions like deforest and urbanization action.

KEYWORDS: Microclimate Changes; Anthropogenic Actions; Natural Variability.

\footnotetext{
1 Instituto de Astronomia, Geofísica e Ciências Atmosféricas (USP). fnatal_oliveira@yahoo.com.br

2 Universidade Federal do Amazonas. ruie@ufam.edu.br

3 Universidade Federal do Amazonas, Instituto de Ciências Exatas, Departamento de Geociências. jscarvalho@ufam.edu.br

${ }^{4}$ Sistema de Proteção da Amazônia, Sistema de Proteção da Amazônia, Divisão de Processamento de Imagens. solange.costa@sipam.gov.br
} 


\section{INTRODUÇÃO}

As alterações no microclima de determinada região ocorrem tanto por influências antropogênicas, como urbanização e agricultura (Kalnay \& Cai, 2003), quanto por emissões de gases de efeito estufa. Ademais, os fenômenos atmosféricos de grande-escala, tais como o El Niño - Oscilação do Sul (ENOS) e a Oscilação Decadal do Pacífico, também possuem papel essencial nas variabilidades intrasazonais a decadais do clima.

Das formas de interação na interface atmosfera-solo, a disponibilidade de energia solar é o fator fundamental na determinação das condições climáticas de uma determinada região, pois é o principal agente externo e modificador das demais variáveis, como temperatura e precipitação pluviométrica. Por exemplo, em um ecossistema de floresta, apenas uma pequena fração da radiação solar que incide no dossel, irá efetivamente alcançar a superfície do solo (Nitiou \& Beltrami, 2005). Consequentemente, a substituição de áreas de floresta por pastagens deverá implicar num substancial incremento do total de radiação solar incidente na superfície do solo e, subsequentemente, ocorrerá um rearranjo do balanço de energia naquela interface solo-atmosfera. Tal situação induz um incremento forçado nos valores de temperatura em superfície, que não pode ser atribuído à variação natural do clima como causa, quando necessariamente o agente modificador foi o homem.

$\mathrm{Na}$ Amazônia, estudos realizados simultaneamente em superfícies de floresta e pastagens demonstraram que, em interfaces do tipo floresta-atmosfera, o fluxo de calor é predominantemente no sentido solo-atmosfera, com uma pequena componente de fluxo no sentido da atmosfera-solo durante o dia, enquanto em interfaces do tipo pastagematmosfera, o fluxo de calor ocorre com elevada magnitude nos dois sentidos, dependendo se o período for seco ou chuvoso (Souza et al, 1996). Esse fluxo de calor tende a se propagar lentamente em direção ao subsolo, sendo atenuado lentamente com o incremento da profundidade e alterando as propriedades térmicas normais da estrutura geotérmica rasa (Silva,2003; Astier, 1975; Beck, 1965; Bowen, 1966; Carslow \& Jaeger, 1959). Outros trabalhos executados na Amazônia registraram perturbaçōes térmicas em profundidades de até 250 metros (Serra, 2002), permitindo concluir que tais variaçōes termais persistem a maiores profundidades (Araujo e Silva, 1982; Araujo et al, 1984; Araujo et al, 1985; Araujo, 1987; Araujo et al, 1991; Araujo, 1999; Souza et al, 1996; Silva, 2003; Serra, 2002).

O uso dessas perturbações térmicas com a finalidade de estudos climáticos foi impulsionado por Lachenbruch \& Marshall (1986), que analisaram perfis geotérmicos na região ártica do Alaska e verificaram um aquecimento de $2{ }^{\circ} \mathrm{C}$ a 5 ${ }^{\circ} \mathrm{C}$. Anteriormente, Roy et al (1971) haviam determinado um incremento nos valores das temperaturas médias superficiais do solo de $5^{\circ} \mathrm{C}$ em um período de 50 anos, para a região de Cambridge, Massachusetts (USA). Contudo, seus estudos tiveram como objetivo fundamental, apenas calcular o fluxo geotérmico profundo, ou fluxo de calor produzido no interior da Terra, desprezando os estudos climáticos pertinentes da geotermia rasa. Segundo esses autores, tal acréscimo foi decorrente da construção de edifícios na região em pauta. Conforme o Painel Intergovernamental de Mudanças Climáticas (IPCC, sigla em inglês) de 2001, o aquecimento global medido por dados geotérmicos é de aproximadamente $1,0 \pm 0,3^{\circ} \mathrm{C}$, durante os últimos 5 séculos, com maior atribuição a partir do século XIX. Entretanto, com base em 826 perfis geotérmicos ao redor do globo terrestre, o aquecimento global é de aproximadamente $0,45^{\circ} \mathrm{C}$ nos últimos 200 anos e de $0,9^{\circ} \mathrm{C}$ nos últimos cinco séculos (Beltrami, 2002). No entanto, muitos desses perfis geotérmicos analisados estão na América do Norte e Europa Central, e ainda, Sul da África e Austrália, havendo pouca informação para a América do Sul e nenhuma na Bacia Amazônica, onde o efeito do desmatamento em regiáo tropical sobre as temperaturas de superfície deve ser mais bem entendido e quantificado.

De outro lado, os efeitos dos fenômenos naturais de grande escala, como o El Nino - Oscilação do Sul (ENOS) no clima da América do Sul, têm sido bem documentados, em particular as modificações via célula de Walker (Souza et al, 2005; Souza \& Ambrizzi, 2002). Segundo Molion (2004), são os oceanos a condição de contorno inferior mais importante para aquecimento da atmosfera e das variabilidades climáticas interdecadais, visto que a atmosfera terrestre é aquecida por baixo. Dentre os oceanos, o Pacífico possui papel de destaque, já que é a maior massa marítima do globo terrestre e ocupa sozinho, quase um terço da superfície terrestre. Com aproximadamente 180 milhôes de $\mathrm{km}^{2}$, é praticamente a metade de toda área oceânica. Nesse aspecto, consideramos que o Oceano Pacífico e suas flutuaçôes oceânico-atmosféricas de larga-escala importam diretamente nas variabilidades intersazonais a decadais do clima sobre as áreas continentais. Segundo Kousky e Cavalcanti (1984), a variabilidade interanual da precipitação pluviométrica na América do Sul é modulada pelo ENOS e, na Amazônia, estudos indicaram desvios negativos de precipitação pluviométrica durante eventos de El Niño (Kayano \& Moura, 1986; Aceituno, 1988; Souza et al, 2000). Isto, porque eventos de El Nino, durante o período chuvoso na Amazônia Central, afetam o posicionamento dos sistemas dinâmicos geradores de chuva, reduzindo a umidade do ar, inibindo a convecção e ocasionando períodos de seca e temperaturas acima da média em períodos climatológicos chuvosos. Em contrapartida, os eventos de La Nina, de acordo com as observaçôes produzem maiores totais de chuva. 
Mantua et al (1997) descreveram outro fenômeno de larga-escala no Pacifico, propriamente no setor norte da Bacia do Pacífico, denominado de Oscilação Decadal do Pacífico (ODP). Este fenômeno é semelhante ao fenômeno ENOS, porém, com oscilações da temperatura superficial de prazo mais longo, um ciclo de 50 a 60 anos, com 20 a 30 anos para cada fase, fria e quente. Esses mesmos autores observaram uma forte correlação entre os índices monitores de tais fenômenos, como o IOS e o CTI (Cold Tongue Index), onde as condições da fase quente (fria) do ENOS tendem a coincidir com os anos de predominância da fase quente (fria) ou polaridade positiva (negativa), da ODP. Ainda citaram que a fase da ODP foi predominantemente positiva entre 1925 e 1946, negativa entre 1947 e 1976 e novamente positiva desde 1977 até 1998.

Desse modo, este trabalho foi dividido em duas partes, com enfoques distintos. Primeiramente tratamos das séries dos perfis geotérmicos, onde o uso do solo foi tomado como o fator primário para as mudanças de temperatura do solo junto à superfície e, em seguida, realizada uma análise observacional das anomalias da temperatura média do ar de superfície (ATS) da estação meteorológica de Manaus, verificando suas possíveis relaçôes com as anomalias das temperaturas superficiais (ATSM) no Pacífico tropical, tratando a variabilidade natural do clima como fator preponderante.

Pretendemos, assim, enfatizar que mudanças no microclima podem ser decorrentes tanto de fatores climáticos, quanto de fatores não necessariamente climáticos, em especial aqueles relativos ao uso do solo, e determinar quantitativamente, a contribuição efetiva de cada fator, antrópico e natural, para os valores de temperatura média no microclima da cidade de Manaus (AM).

\section{MATERIAL E MÉTODOS}

\section{SÉRIE DE DADOS GEOTÉRMICOS}

Neste estudo analisamos os perfis geotérmicos de onze furos distribuídos na cidade de Manaus, com período médio de perfilagens pós-perfuração de 11 anos. Desses, seis poços com cobertura vegetal (LCCV) e cinco poços sem cobertura vegetal (LSCV), conforme apresentado na Figura 1. As medições de temperatura foram realizadas em intervalos discretos de 5 metros e profundidade de até 300 metros, cujos pontos de observação estão distribuídos sobre a área urbana de Manaus, conforme representado na Figura 1.

Nas perfilagens rasas superficiais, até $0,20 \mathrm{~m}$, foram utilizadas sondas com sensor térmico de termopar, com precisão de precisão de $\pm 0,1^{\circ} \mathrm{C}$ (Araújo, 1999). Nas perfilagens mais profundas, o sensor térmico foi, um termistor, com precisão de $\pm 0,01{ }^{\circ} \mathrm{C}$ (Araujo, 1999). Assim, obteve-se as temperaturas superficiais do solo $\left(\mathrm{T}_{\mathrm{SP}}\right)$ e, aquelas profundidades analisadas,
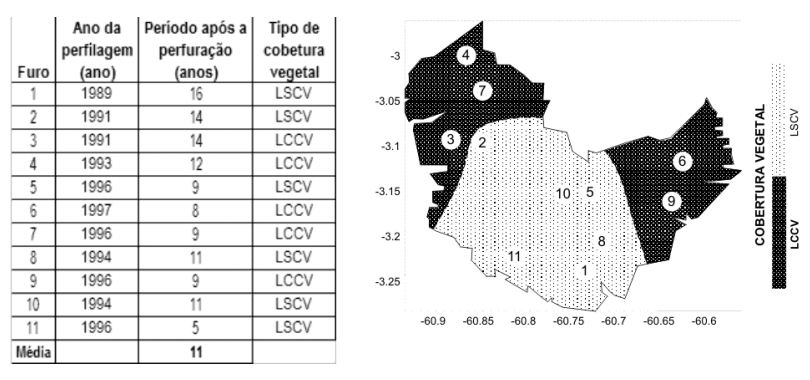

Figura 1 - Localização dos gerfis geotérmicos em Manaus - AM.

que apresentaram sinais de perturbações térmicas oriundas da superfície terrestre, constituiram-se palco da geotermia rasa.

Pelo exposto, para determinar a variação das temperaturas superficiais consideramos a hipótese de Roy et al (1971) de um perfil geotérmico inicial, referente ao período anterior às atividades antrópicas, ou seja, antes do rearranjo do balanço de energia superficial. Nosso método não pode inferir exatamente o período do rearranjo térmico superficial, contudo é estimado que o rearranjo térmico tenha se iniciado juntamente com o processo de urbanização do Município de Manaus. Para esse perfil inicial, assumimos três condiçōes básicas: a) o material litológico é homogêneo; b) está termicamente em equilíbrio; e c) a superfície terrestre assume comportamento adiabático. $\mathrm{O}$ resultado é que o perfil geotérmico iniciaria na superfície, com o valor da temperatura média anual superficial do solo anterior às atividades antrópicas (pré-rearranjo térmico da interface solo-atmosfera), doravante denominadas de $\mathrm{T}_{\mathrm{LD}}$, e os valores de temperatura aumentariam gradual e linearmente com a profundidade, visto que as variaçôes térmicas neste perfil são funçôes, apenas, do fluxo de calor oriundo do interior da Terra (fluxo geotérmico). Este perfil foi denominado de Perfil Inicial. Considerando as perturbações de superfície, pós-atividades antrópicas, encontramos um perfil térmico, denominado de Perfil Final, onde obtivemos os valores atuais das temperaturas médias anuais da superfície do solo $\left(\mathrm{T}_{\mathrm{SA}}\right.$. Esse Perfil Inicial é, portanto, função tanto do fluxo geotérmico, quanto do fluxo de radiação solar e, ainda, levou-se em conta o tipo de vegetação e a variabilidade sazonal de chuva.

Conforme Roy et al (1971), a extrapolação da reta, que determina o gradiente geotérmico profundo, possibilita o cálculo da $T_{\mathrm{LD}}$. Conforme Araujo (1999), a extrapolação da reta, logo após a inversão térmica subsuperficial, possibilita apenas o cálculo da $T_{S A}$. Logo, a $T_{L D}$ somente é obtida a partir das profundidades onde não sejam registradas influências oriundas de perturbaçōes térmicas do clima, região denominada de Zona Termicamente Estável (ZTE). A zona superior do subsolo superior, que apresenta variaçôes térmicas, foi denominada de Zona Termicamente Perturbada (ZTP).

Os valores da $\mathrm{T}_{S \mathrm{~A}}$ e da $\mathrm{T}_{\mathrm{LD}}$ foram obtidos através do Perfil Geotérmico Inicial, projetado a partir de equaçōes lineares, 
e calculadas, ponto a ponto, com base no valor prévio do gradiente geotérmico médio do local $(\Gamma)$. Os cálculos pontuais nos permitem obter os valores das temperaturas dos Perfis Iniciais e Finais $\left(T_{(\mathrm{z})}\right)$ para cada nível de profundidade do perfil. As seguintes equações lineares foram empregadas, assumindo que a superfície possui um comportamento adiabático:

$$
T_{(z)}=-\left(\Gamma_{z T E} * z-T_{r e f}\right)(1) \text { e } T_{(z)}=\Gamma_{Z T P} * z+T_{r e f}
$$

sendo, $T_{(Z)}=T_{L D}$ na Equação $1 \mathrm{e}, T_{(Z)}=T_{S A}$ na Equação 2, ambos em $z=0$ e, onde os $\Gamma_{\text {ZTE }}$ e $\Gamma_{\text {ZTP }}$ são os gradientes geotérmicos médios para as zonas termicamente estáveis e termicamente perturbadas, respectivamente. $Z$ é a profundidade num determinado nível e $T_{\text {ref }}$ é a temperatura de referência ajustada à superfície e, necessariamente, $T_{\text {ref }}$ = $T_{(Z)}$, quando $Z$ for igual à zero, satisfazendo às condiçóes de um perfil linear e adiabático.

O conjunto de perturbações térmicas, ou série temporal longa de dados (pré-atividades antrópicas) e transientes (atual), foram obtidas por cálculos de resíduos térmicos referentes aos Perfis Inicial e Final, conforme as equaçôes que se seguem:

Analisando a ZTE (região profunda do perfil), tomou-se, por base, o valor médio do gradiente local $\left(\Gamma_{\mathrm{ZTE}}\right)$, e a equação válida é:

$$
\mathfrak{R}_{i}=T_{O B S}-T_{(Z)}
$$

Para a ZTP (região rasa do perfil), tomou-se, por base, o valor médio do gradiente local $\left(\Gamma_{\mathrm{ZTP}}\right)$ e, nesse caso a equação válida é:

$$
\mathfrak{R}_{f}=T_{O B S}-T_{(Z)}
$$

onde $\mathfrak{R}_{f}$ são os resíduos de temperatura transientes ou perturbações térmicas transientes. E, ainda, calculou-se:

$$
\mathfrak{R}_{i-f}=\mathfrak{R}_{i}-\mathfrak{R}_{f}
$$

onde $\mathfrak{R}_{\text {i-f }}$ são os resíduos de temperatura, ou perturbações térmicas, de longo-prazo.

Nas equações 3 e 4, $T_{O B S}$ é a temperatura observada nas perfilagens geotérmicas. Já a equação 5 faz-se necessária, no intuito de eliminar as perturbaçôes transientes de temperatura, associadas às intempéries climáticas de superfície, com relação ao período anterior às atividades antrópicas sobre a área superficial local do perfil. Desse modo, o tempo de ocorrência da mudança de temperatura superficial, foi considerado como tendo ocorrido a partir da segunda metade do século XIX, a qual corresponde ao início das perturbações antrópicas de maior impacto no solo de Manaus. Contudo, ressalta-se que as alteraçôes no microclima pelo uso do solo, independem dos fenômenos de grande escala atmosférica e ocorrem de forma quase que instantânea. Assim, os resultados das perfilagens geotérmicas propiciaram a obtenção dos dados necessários à realização de estudos para efeitos do uso do solo no microclima de Manaus (AM).

\section{SÉRIE DE DADOS METEOROLÓGICOS}

Calculamos e analisamos uma série de dados de anomalias de temperatura média mensal do ar (ATS), pertencentes ao banco de dados de temperatura média do ar da Estação Climatológica Principal de Manaus (Esmet de Manaus) do INMET, referentes ao período de 1921 a 2000, e comparamos com as anomalias de temperatura superficiais do mar (ATSM) do Pacífico na região Niño $3.4\left(120^{\circ} \mathrm{W}-170^{\circ} \mathrm{W}\right.$ e $5^{\circ} \mathrm{S}-$ $5^{\circ} \mathrm{N}$ ) obtidas de Trenbert \& Stepaniak (2001) para o mesmo período. A série de ATSM é oriunda das análises do banco de dados do Haddley Centre Global Sea Ice and Sea Surface Temperature (HadISST), desenvolvido pelo Met Office Haddley Centre, Reino Unido. O HadISST consta de uma série de dados de TSM de 1870 até a presente data, estimados por observaçóes e derivados de produtos de satélite, com resolução global $1^{\circ} \times 1^{\circ}$.

O motivo da escolha não convencional do período de 1950-79 como base da normal climatológica, contrariando ao adotado pela Organização Meteorológica Mundial (OMM) de 1961-90, está associado às observações de Molion (2004), onde aquele autor notadamente salientou que tal período, sugerido pela OMM, poderia mascarar estudos de tendências de temperatura, visando à importância da Oscilação Decadal do Pacífico (ODP). Molion (2004) concluiu que o período climatológico adotado pela OMM (1961-1990) consta com 16 anos dentro da fase negativa (1947-1976) da ODP e 14 anos dentro da fase positiva (1976-1998) da ODP, de modo que se os efeitos dos dois períodos forem opostos, teríamos uma média quase-perfeita para o período, eliminando tendências de longo-prazo.

Com o objetivo de determinar como e quanto cada evento do ENOS (El Niño - fase quente, La Niña - fase fria e neutros) contribuiu para as variabilidades da temperatura média do ar, separamos o ciclo anual em períodos trimestrais, classificados de acordo com padrôes normais de precipitação, descrito por Oliveira (2006), que utilizou o Índice dos Decis de Gibbs \& Maher (1967). A separação em períodos trimestrais fezse necessária devido ao uso dos conceitos de estação seca e estação chuvosa em regióes tropicais, as quais substituem os conceitos de verão e inverno das estações de latitudes médias (Riehl, 1965). Conforme Oliveira (2006), o início e término do período chuvoso ocorrem de dezembro a maio, enquanto o período de junho a novembro corresponde ao início e término do período seco. Assim, usando o proposto por Oliveira (2006), os trimestres chuvosos e secos foram distribuídos como se segue (Figura 2): o primeiro e segundo trimestres chuvosos, de dezembro a fevereiro - DJF (1TC) e de março a maio - MAM (2TC), respectivamente; o primeiro e segundo 


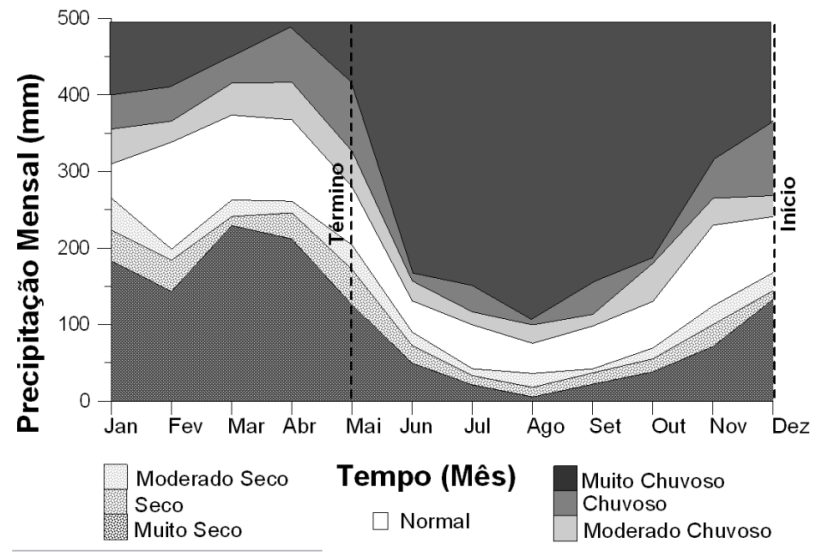

Figura 2 - Classificação dos padrões de precipitação para Manaus. Fonte: Oliveira (2006)

trimestres secos de junho a agosto - JJA (1TS) e setembro a novembro - SON (2TS), respectivamente.

Para o cálculo das tendências de temperatura média do ar em Manaus, optou-se por uma análise de regressão linear simples do tipo:

$$
T=D^{*} A+I
$$

onde $T$ é a variável Temperatura média do ar, $D$ é a inclinação da reta, $A$ é o ano correspondente e $I$ é a interseção.

Os meses das fases quente e fria do ENOS foram classificados conforme Trenbert (1997), para a região Niño 3.4, quando as anomalias de TSM na região excedem o valor de $0,4^{\circ} \mathrm{C}$ (El Niño) e $-0,4^{\circ} \mathrm{C}$ (La Niña), respectivamente, e persistem, no mínimo, por seis meses.

\section{RESULTADOS}

\section{PERFIS GEOTÉRMICOS}

Conforme a Figura 3, nos perfis do tipo LCCV determinamos gradientes positivos de magnitude pequena, desde a superfície do subsolo até as maiores profundidades investigadas, enquanto nos perfis do tipo LSCV verificamos gradientes negativos, com magnitudes elevadas, desde a superfície até profundidades de 30 a 80 metros, seguidos de uma zona com fluxo de calor nulo, denominada por Araujo (1999) de "zona de cotovelo térmico", e de uma zona de inversão térmica em profundidades médias de $78 \mathrm{~m}$, a partir da qual a temperatura aumenta linearmente com a profundidade. As observaçōes dessas condiçōes nos permitiram admitir que a Zona Termicamente Perturbada (ZTP) se encontra dividida em dois setores (Figura 4), onde a porção superior está associada a dados transientes devido a variabilidade climática sazonal e anual, enquanto a porção inferior, após a zona do cotovelo térmico, está associada às informaçōes de longo-

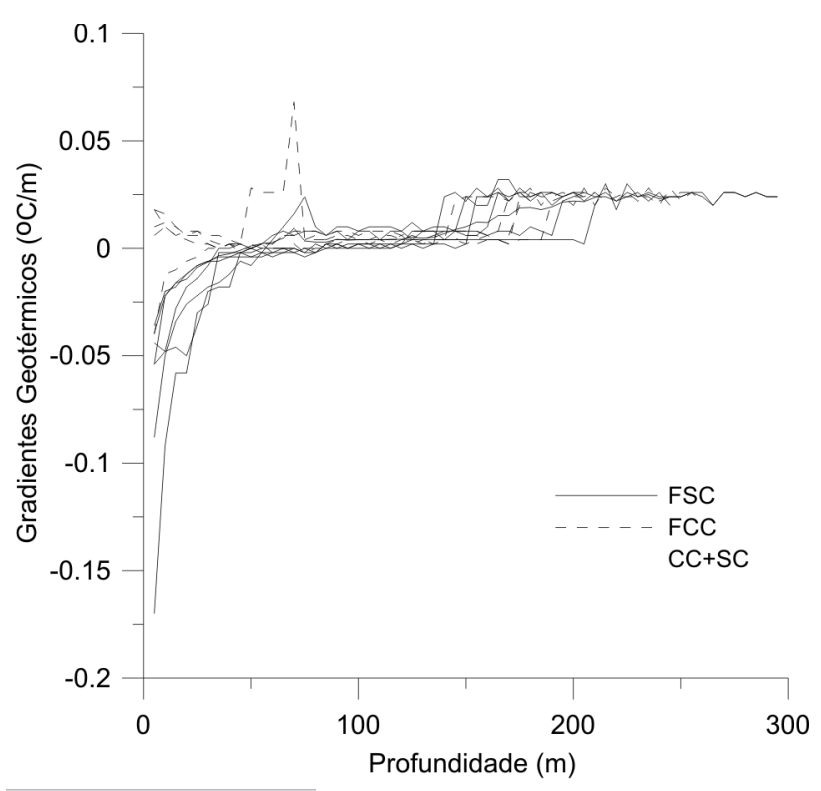

Figura 3 - Gradientes geotérmicos da região de Manaus (AM). FSC - furo sem cobertura, FCC - furo com cobertura, CC + SC - média de todos os furos.

prazo. Desse modo, passamos a admitir os termos $Z_{T P}{ }_{\text {ITR }}$ e ZTP $_{\text {ILD }}$, como designativos da divisão da Zona Termicamente Perturbada.

Nos perfis LCCV encontramos os gradientes médios de $5 \times 10^{-3} \pm 1,5 \times 10^{-3}{ }^{\circ} \mathrm{C} \cdot \mathrm{m}^{-1}$ e $2,42 \times 10^{-2} \pm 4 \times 10^{-4}{ }^{\circ} \mathrm{C} \cdot \mathrm{m}^{-1}$ para $\Gamma_{\text {ZTP }}$ e $\Gamma_{\text {ZTE }}$, respectivamente. Para os perfis LSCV, encontramos $4,9 \times 10^{-3} \pm 3,3 \times 10^{-3}{ }^{\circ} \mathrm{C} . \mathrm{m}^{-1}$ e $2,43 \times 10^{-2} \pm$ $5 \times 10^{-4}{ }^{\circ} \mathrm{C} . \mathrm{m}^{-1}$, para $\Gamma_{\mathrm{ZTP}}$ e $\Gamma_{\mathrm{ZTE}}$, respectivamente. Nota-se

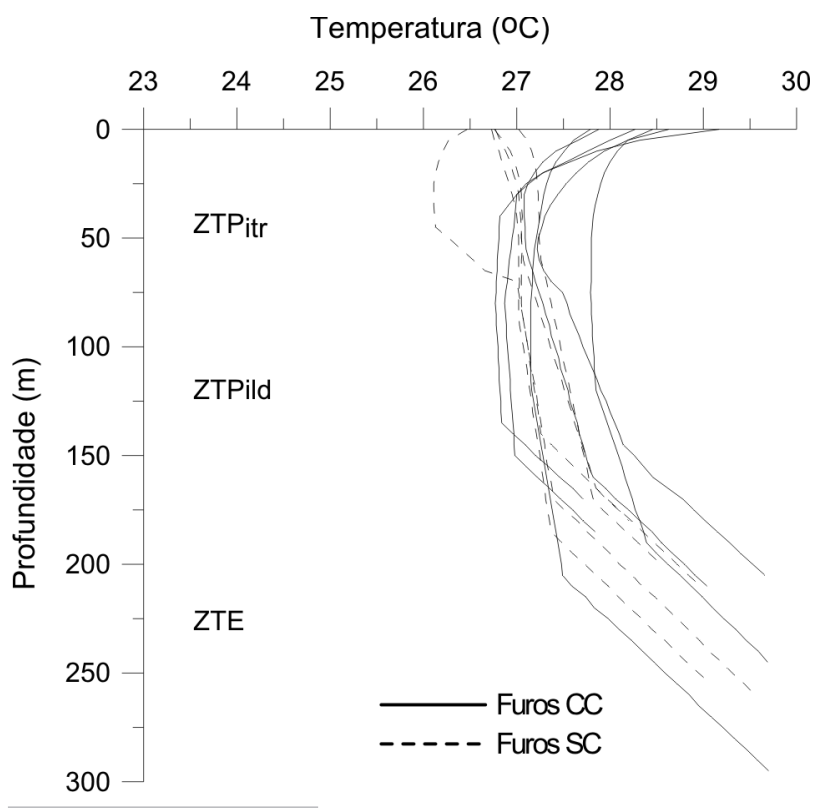

Figura 4 - Perfis de temperatura verso profundidade dos furos em Manaus (AM). Furos CC são relativos aos furos com cobertura vegetal, e SC sem cobertura vegetal. 
que os valores de $\Gamma_{\text {ZTP }}$ e $\Gamma_{\text {ZTE }}$ para os dois tipos de cobertura vegetal são muito próximos. Tal valor aproximado deve-se a ausência de perturbaçōes transientes de superfície nas regiōes ZTP $_{\text {ILD }}$ e ZTE. Dessa forma, observou-se que, a partir das profundidades médias de 78 metros $\left(\mathrm{ZTP}_{\text {IID }}\right)$ e 165 metros (ZTE), os perfis adquiriram padrões com inclinaçōes semelhantes (Figuras 3 e 4). Não obstante, os valores médios de $\Gamma_{\text {ZTP }}$ e $\Gamma_{\text {ZTE }}$ para o conjunto global dos perfis foram de $4,9 \times 10^{-3} \pm 2,5 \times 10^{-3}{ }^{\circ} \mathrm{C} . \mathrm{m}^{-1}$ e $2,43 \times 10^{-2} \pm 5 \times 10^{-4}{ }^{\circ} \mathrm{C} \cdot \mathrm{m}^{-1}$, respectivamente.

Nota-se que na região ZTP ${ }_{\text {ITR }}$ os gradientes negativos, identificados nos perfis LSCV e positivos nos perfis LCCV, são oriundos da variabilidade climática local sazonal e anual (Figura 4). Já os gradientes superficiais em locais do tipo LSCV fornecem um conjunto de informações transientes oriundas tanto das intempéries climáticas como das atividades antrópicas, associadas ao uso do solo. Ambos os gradientes negativos e positivos dessas regiōes superficiais podem ser considerados temporais de alta variabilidade, enquanto o campo das perturbaçōes térmicas referentes às informaçôes de longo-prazo $\left(\mathrm{ZTP}_{\mathrm{IID}}\right)$ persistem até as profundidades médias de 165 metros e, abaixo dessas profundidades, não foram encontradas perturbações oriundas do campo climático temporal de superfície.

Em base nos valores observados nos campos de temperatura dos perfis térmicos, calculamos os valores médios de $\mathrm{T}_{S \mathrm{P}}$ de $26,75 \pm 0,20{ }^{\circ} \mathrm{C}$ e $28,37 \pm 0,51{ }^{\circ} \mathrm{C}$ e amplitudes térmicas de $0,55^{\circ} \mathrm{C}$ e $1,38^{\circ} \mathrm{C}$ para os perfis LCCV e LSCV, respectivamente. Assim, os valores médios de $\mathrm{T}_{\mathrm{SP}}$ nos perfis

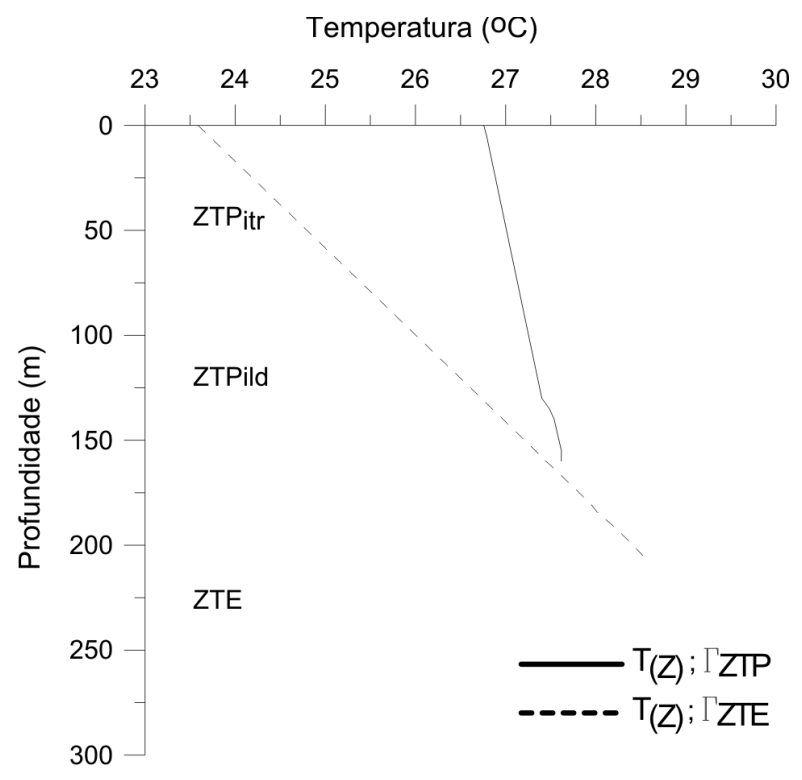

Figura 5 - Inferência das temperaturas médias anterior ao rearranjo térmico e atual em Manaus (AM).
LSCV foram $1,62{ }^{\circ} \mathrm{C}$ maiores que os valores nos perfis LCCV. Tal diferença foi atribuída às mudanças ocorridas no balanço de energia do solo perante a substituição das áreas de floresta por pastagens. Desse modo, concluímos que a retirada da floresta gerou um incremento médio na média anual de $+1,62^{\circ} \mathrm{C}$.

Na figura 5 , representamos o cálculo dos Perfis Geotérmicos Inicial $\left(T_{(Z)} ; \Gamma_{\mathrm{ZTE}}\right)$ e Final $\left(T_{(Z)} ; \Gamma_{\mathrm{ZTP}}\right)$, sendo os valores médios de $\mathrm{T}_{\mathrm{SA}}$ e $\mathrm{T}_{\mathrm{LD}}$, de 26,76 $\pm 0,10^{\circ} \mathrm{C}$ e $23,59 \pm 0,54^{\circ} \mathrm{C}$, respectivamente.

A Figura 6 representa os resíduos $\mathfrak{R}_{f}$ (transientes) dos perfis geotérmicos analisados, enquanto a Figuras 7 representa os resíduos $\mathfrak{R}_{\text {iff }}$ (longo-prazo). Nessas figuras, os valores dos incrementos de temperatura em superfície de longo-prazo foram lidos diretamente na linha de temperatura à superfície do perfil, pela reta dada por $\mathfrak{R}_{i-f}$. As profundidades, onde não se verificaram perturbações térmicas de superfície, foram identificadas nas figuras, pelo valor de $\mathfrak{R}_{i}=0$. O valor do resíduo $\mathfrak{R}_{f}$ (transientes) em superfície nos possibilitou estimar a recente variabilidade climática sazonal e anual individual de cada perfil, associada às variaçōes climáticas na superfície.

\section{Figura 6}

Na Figura 6.a é interessante observar que os valores correspondentes aos resíduos transientes dos poços do tipo LCCV têm magnitude próxima de zero; esse comportamento foi verificado desde a superfície até as maiores profundidades, enquanto que, os valores referentes aos resíduos dos poços do tipo LSCV (figura 6.b), apresentaram valores com magnitude muito elevada. Dessa maneira, concluiu-se que tais diferenças são características da intensidade da radiação solar incidente na superfície e do fluxo de calor ganho ou perdido pelo subsolo para a atmosfera. Os conteúdos de umidade do solo e precipitação, também são fatores que influenciam os valores dos resíduos transientes.

Ainda, conforme a figura 6, observa-se, nos perfis LCCV, pouco ou nenhum sinal de variabilidade climática anual em superfície, cerca de $+0,03 \pm 0,18^{\circ} \mathrm{C}$ (Figura 6.a), confirmando a papel da cobertura vegetal como agente filtrador da radiação solar incidente, enquanto nos perfis LSCV, verificou-se uma recente variabilidade climática anual de $+1,58 \pm 0,51{ }^{\circ} \mathrm{C}$ (Figura 6.b). Os elevados valores de dispersão dos desvios padrōes representam alta variabilidade entre as informaçôes transientes. Tais valores podem ser alterados conforme o período ou época do ano analisada.

Na Figura 7 apresentamos os resultados obtidos dos resíduos térmicos de longo-prazo, onde verificamos um acréscimo médio nas temperaturas médias superficiais do solo, para os perfis do tipo LSCV, de $+3,15 \pm 0,65^{\circ} \mathrm{C}$ (Figura 7.a) e 

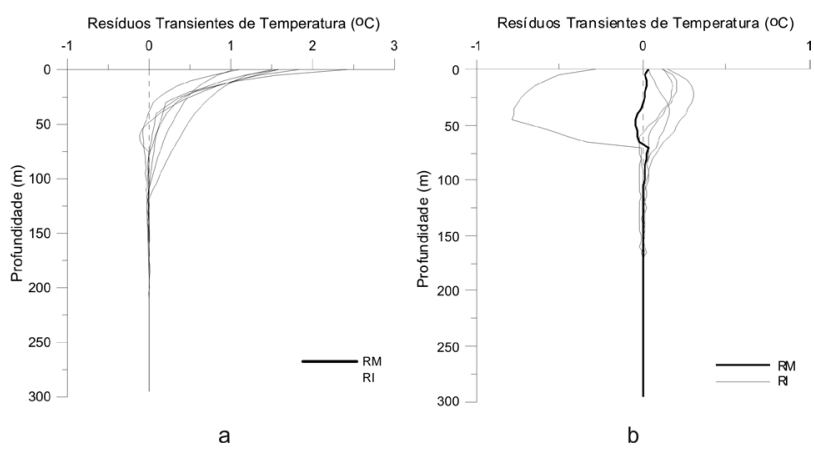

Figura 6 - Resíduos térmicos transientes de temperatura do subsolo do tipo (a) LCCV e (b) LSCV. RM é o valor residual médio e RI são os valores residuais individuais de $\mathfrak{R}_{f}$ para cada perfil.

$\mathrm{de}+3,19+0,42{ }^{\circ} \mathrm{C}$ (Figura 7.b) para os perfis do tipo LCCV. Tais valores são característicos das condições climáticas da região de Manaus, podendo ser encontrados valores distintos para outras regiōes do globo.

Observa-se na Figura 7, que todos os perfis geotérmicos apresentados indicaram um acréscimo nos valores das temperaturas superficiais do solo, onde o acréscimo, nos perfis $\mathrm{LCCV}$, foi $+0,04^{\circ} \mathrm{C}$ maior que nos perfis LSCV. Contudo, tal diferença de $0,04^{\circ} \mathrm{C}$ é muito inferior aos valores de desvio-padrão e não consideramos como um sinal de relativa importância, significando que as taxas de acréscimo de longoprazo nas temperaturas médias superficiais do solo, foram praticamente iguais para superfícies com ou sem cobertura vegetal, por serem determinadas a partir de regiōes do subsolo atinentes a informaçóes de longo-prazo. $\mathrm{O}$ mesmo pode não ser válido para as recentes variabilidades climáticas anuais, visto serem função apenas do fluxo de radiação solar em superfície e determinadas na ZTP ${ }_{\text {ITR }}$.

Para ratificar que os dados transientes de locais protegidos por cobertura vegetal podem indicar boas resoluções anuais das
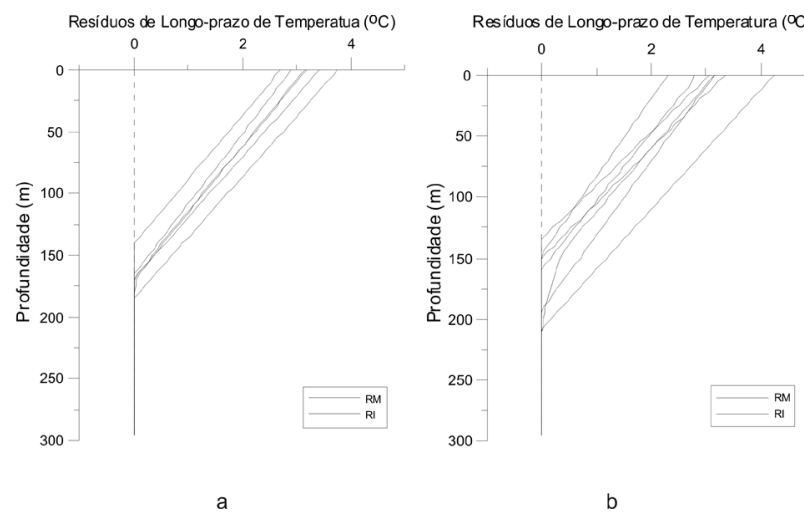

Figura 7 - Resíduos térmicos de longo-prazo de temperatura do subsolo do tipo (a) LCCV e (b) LSCV. RM é o valor residual médio e RI são os valores residuais individuais de $\mathfrak{R}_{i-f}$ para cada perfil. recentes variabilidades climáticas, analisamos as perturbações transientes dos perfis LCCV, relativos ao período dos anos de 1991-1993-1996 e 1997, com a média móvel de 5 meses das ATS, referentes aos anos completos de 1991-1993-1996 e até abril de 1997 (Figura 8). A análise foi realizada somente até o mês de abril de 1997, devido ao clássico El Niño de abril de 1997 a março de 1998, o qual poderia causar severas discrepâncias nos resultados.

Na Figura 8, observa-se que o desvio na temperatura média do ar foi de $+0,17 \pm 0,08{ }^{\circ} \mathrm{C}$. Tal valor está de acordo com as informações transientes dos perfis LCCV de $+0,03 \pm$ $0,18^{\circ} \mathrm{C}$, o qual oscila de $-0,15^{\circ} \mathrm{C} \mathrm{a}+0,21^{\circ} \mathrm{C}$. Isso ratificou a ligação entre as informações transientes do subsolo de locais com cobertura vegetal com as variabilidades climáticas detectadas em superfície. A exceção foi para os meses de julho e agosto (meses geralmente secos ou pouco chuvosos), onde foram verificadas ATS maiores do que os valores residuais transientes de superfície. Apesar da comparação realizada não ser produto de um monitoramento contínuo, os resultados foram plausíveis, sugerindo a elaboração de um experimento controlado para melhor apurar esses resultados.

Nos perfis do tipo LSCV, tais comparações são muito problemáticas, visto que as mudanças na cobertura vegetal alteram significativamente o balanço de energia na superfície do solo (Ferguson, 2005). Isso foi verificado pela discrepância dos dados. Contudo, os dados obtidos nos perfis LSCV mostraram a importância das modificações no clima regional por forçantes antrópicas.

\section{ANÁLISE DA TEMPERATURA MÉDIA OBSERVADA DO AR}

A estação meteorológica de Manaus situa-se na região nordeste do Estado do Amazonas, Brasil (60,02 ${ }^{\circ} \mathrm{W}$ e 2,13응 $S)$. Com base na série de dados do INMET, utilizando o período de 1950-79, calculamos as médias mensais da temperatura do ar e o valor médio anual foi de 26,65 \pm $0,33{ }^{\circ} \mathrm{C}$. As temperaturas médias foram mais baixas durante os meses de fevereiro e março, com valores de $25,8{ }^{\circ} \mathrm{C}$, podendo alcançar valores ligeiramente abaixo de $25,0{ }^{\circ} \mathrm{C}$ e

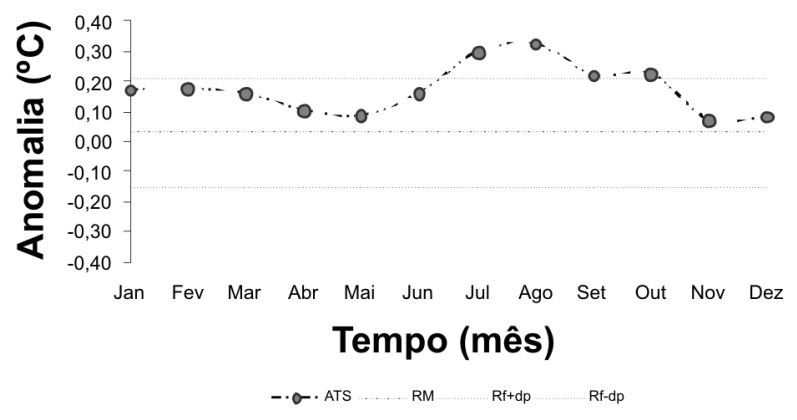

Figura 8 - Comparação das TSP verso ATS para os locais do tipo LCCV. 
os maiores valores foram observados nos meses de agosto a outubro, com médias de $27,4^{\circ} \mathrm{C}$ a $27,9^{\circ} \mathrm{C}$, respectivamente, podendo o máximo das médias alcançar valores de $28,8{ }^{\circ} \mathrm{C}$ e $30.2{ }^{\circ} \mathrm{C}$, respectivamente. Ainda na Figura 9, verificou-se que a amplitude anual das temperaturas médias do ar foi de 2,1 ${ }^{\circ} \mathrm{C}$, devido aos altos valores de energia da radiação solar incidente na superfície terrestre ao longo de todo o ano e os desvios da temperatura média foram maiores durante os meses de agosto a novembro, no trimestre seco. As amplitudes térmicas registradas foram pequenas, pela própria característica do clima tropical com elevada radiação solar em superfície ao longo do ano. Desta forma, o clima da cidade de Manaus é regido, fundamentalmente, pelo ciclo anual da chuva.

É notável observar que o valor médio anual de 26,65 $\pm 0,33{ }^{\circ} \mathrm{C}$, observado na estação meteorológica, está em concordância com o valor médio observado para a temperatura média anual atual da superfície do solo de 26,76 $\pm 0,10{ }^{\circ} \mathrm{C}$, considerando o desvio médio. Assim, para as localidades que não possuem estações meteorológicas, torna-se possível obter um padrão climatológico de temperatura por meio de perfis geotérmicos.

Na Figura 9 mostrou-se que a tendência linear, observada para o período de 1921 a 2000, na cidade de Manaus foi de $0,27 \pm 0,04{ }^{\circ} \mathrm{C}$. Observa-se, nessa figura, a variabilidade dos picos de anomalias anuais e o comportamento da média móvel de cinco anos. Tal tendência foi obtida em torno do valor médio calculado da temperatura média do ar de superfície, referente à média climatológica de 1950 a 1979. Para permitir melhor identificação de tendências, suavizamos a curva do comportamento da temperatura média do ar por meio da aplicação de uma média móvel de cinco anos. Desse modo, eliminamos os picos característicos de eventos de curtíssimo prazo.

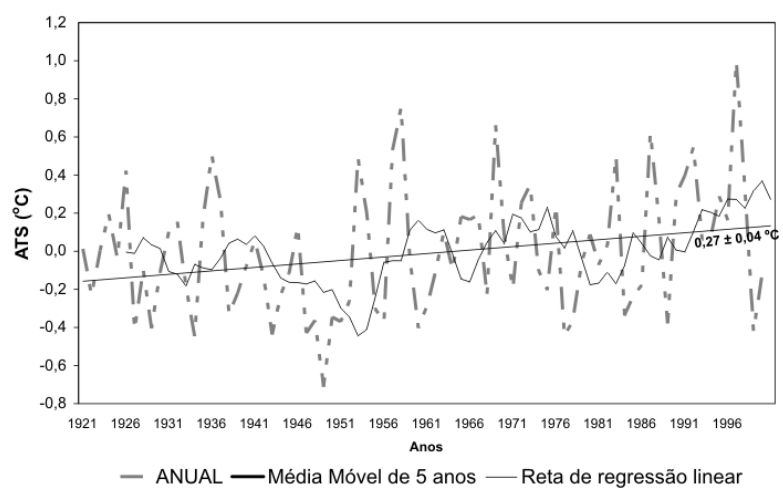

Figura 9 - Tendência observada das anomalias da temperatura média do ar na superfície em Manaus-AM, de 1921 a 2000 com relação à média do período 1950-1979.
Na análise dos dados de temperatura média do ar, efetuamos os cálculos das ATS e relacionamos com as ATSM do Pacífico tropical da região Niño 3.4. O objetivo foi demonstrar a influência dos eventos do ENOS no aquecimento médio representado na Figura 9, que foi de $0,27 \pm 0,4^{\circ} \mathrm{C}$, no período de 1921 a 2000.

Oliveira (2006), usando a metodologia proposta por Trenbert (1997) para a classificação dos eventos do ENOS, encontrou desde 1921 um total de 322 meses na fase quente e 281 meses na fase fria e 352 meses neutros. Dessa classificação, verificamos que os eventos da fase quente geralmente se destacaram pela intensidade das ATS, onde os valores das ATS positivas sobre o continente eventualmente ultrapassaram o valor médio de $1,5^{\circ} \mathrm{C}$ (Figura 10), enquanto os eventos da fase fria se destacaram pela durabilidade do evento, sendo comum uma fase fria durar até 30 meses (Figura 10), embora os valores das ATS dificilmente tenham alcançado o valor médio de $-0,9$ 'C. Nessa figura, destacaram-se os El Niños de 1982-83 e 1997-98 (linha cinza tracejada) e os La Niñas de 1972-76 e 1983-86 (linha cinza cheia) como os eventos de maior influência nas variabilidades das temperaturas do ar em Manaus.

Observa-se na Figura 11, que as ATS negativas durante os trimestres das fases frias e meses neutros contrapuseramse às tendências de aquecimento observadas nos trimestres sob influência das fases quentes. As fases quentes do ENOS contribuíram na elevação das temperaturas médias em até $0,50^{\circ} \mathrm{C}$ (Figura 11) durante os trimestres chuvosos, enquanto, durante as fases frias, verificamos tendências negativas de até

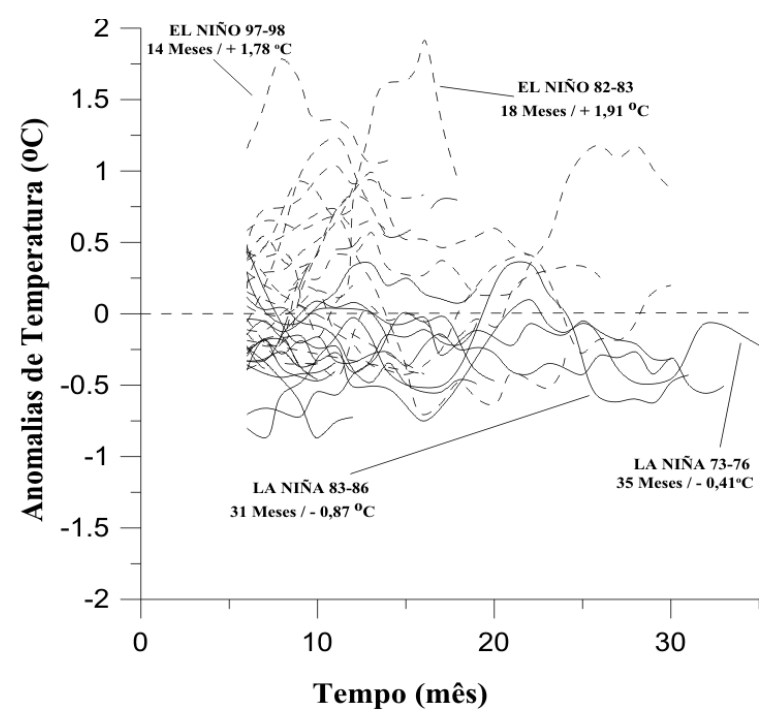

Figura 10 - Média móvel de 5 meses das ATS observadas em Manaus durante as fases do ENOS, El Niño e La Niña. Linhas tracejadas representam eventos completos de El Niño e linhas cheias representam eventos completos de La Niña. Fonte: Oliveira (2006) 
$-0,29^{\circ} \mathrm{C}$, relativas à média do primeiro trimestre chuvoso. Conforme já comentado, a fase quente do ENOS durante o período chuvoso da Amazônia central afeta o posicionamento dos sistemas dinâmicos geradores de chuva, reduzindo a umidade do ar, inibindo a convecção e ocasionando períodos de seca em períodos climatológicos chuvosos, enquanto que o oposto é verificado na fase fria. Portanto, os resultados foram coerentes. Notório foram as tendências negativas das ATS durante os meses neutros.

Analisando as fases do ENOS dentro dos três períodos da ODP, verificou-se maior freqüência de fases quente do ENOS no modo positivo, enquanto a maior freqüência da fase fria do ENOS durante o modo negativo da ODP (Figura 12), concordando com os resultados de Molion (2005). Também observamos, ao longo do tempo, uma redução do número de meses neutros de 136 para 59 meses, entre as duas fases positivas da ODP, os quais aparentemente representam uma redução no período de transição entre as fases quente e fria do ENOS. Desse modo, as séries estudadas apontam que ambas as fases quente e fria do ENOS aumentaram a freqüência de ocorrência ao longo dos últimos 80 anos.

Durante a fase positiva da ODP de 1925-46, apesar da superioridade numérica mensal dos eventos de El Niño sobre

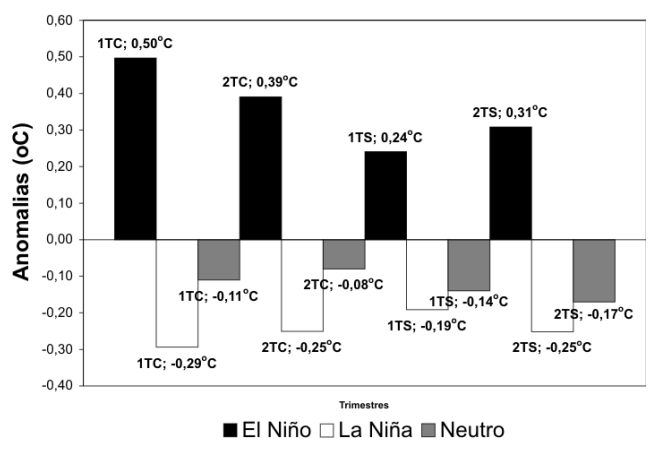

Figura 11 - Contribuição das fases do ENOS para a temperatura média do ar em Manaus-AM.

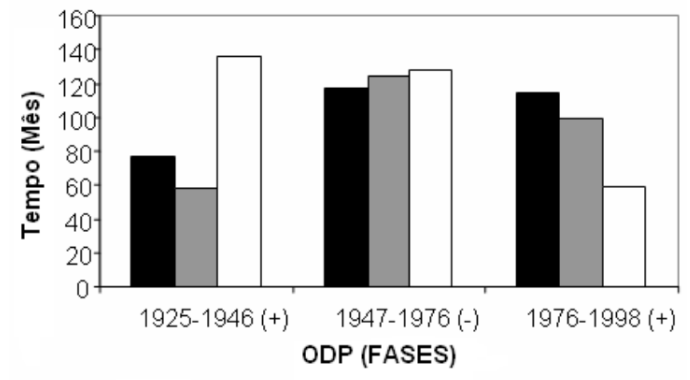

- EL NIÑO LA NINA NEUTROS

Figura 12 - Fases da ODP e a Variabilidade do ENOS no Pacifico Tropical.
La Niñas, não se evidenciou ATS positivas significativas em Manaus, exceto durante o trimestre 1TC do evento jul/25ago/26 (Figura 14-a). Nota-se, entretanto, que as ATS em Manaus durante os eventos de La Niña dessa fase, foram mais significativas (Figura 14-b), praticamente durante todos os trimestres, com predominância durante os períodos secos.

Na Figura 13, referente à fase fria da ODP, aparentemente os eventos de El Niño produziram padrões de anomalias positivas muito significativas, acima de $1{ }^{\circ} \mathrm{C}$ (Figura 13.a), na cidade de Manaus, principalmente no segundo trimestre seco (2TC) e primeiro trimestre chuvoso (1TC). Não foram registradas anomalias negativas significativamente elevadas (Figura 13.b) nos eventos La Niña. Foi observado que os meses neutros predominantemente contribuíram com ATS negativas (Figura 11). Conseqüentemente, a influência da fase
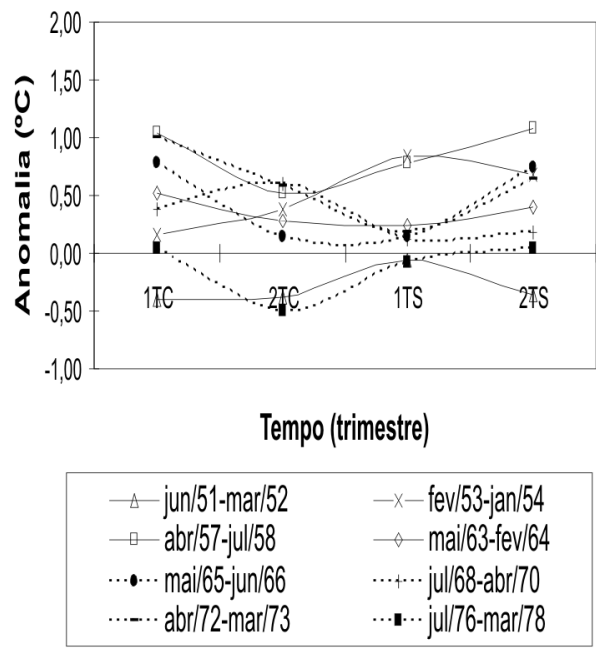

a - Eventos de El Niño

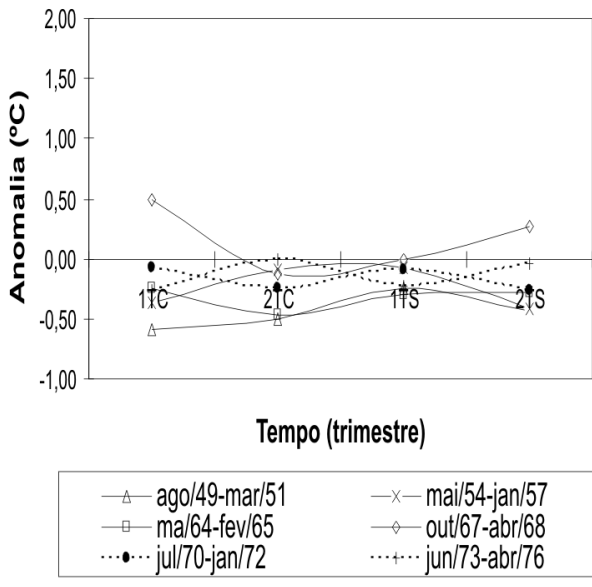

b - Eventos de la Ninã

Figura 13 - Anomalias de temperatura do ar de superfície em Manaus durante a fase negativa da ODP (1947-76). 
negativa da ODP não pôde ser evidenciada somente por uma alta freqüência de La Niñas sobre El Niños na regiāo Niño 3.4, já que houve uma diferença numérica mensal mínima entre Niñas e Niños. Contudo, notou-se que a fase negativa da ODP pode ter produzido uma alta freqüência de meses neutros no Pacifico tropical.

Observa-se, na Figura 14.a, relativa à ultima fase positiva da ODP, um padrão de ATS positivas bastante significativo, aliado à alta freqüência de meses com El Niño (Figura 12). Nessa fase da ODP, é digno de nota que foram dois os eventos clássicos de El Niño, compreendendo o evento de $1982 / 83$ e o evento de 1997/98. No evento de 1982/83, durante o subgrupo 1TC (chuvoso), foram registradas
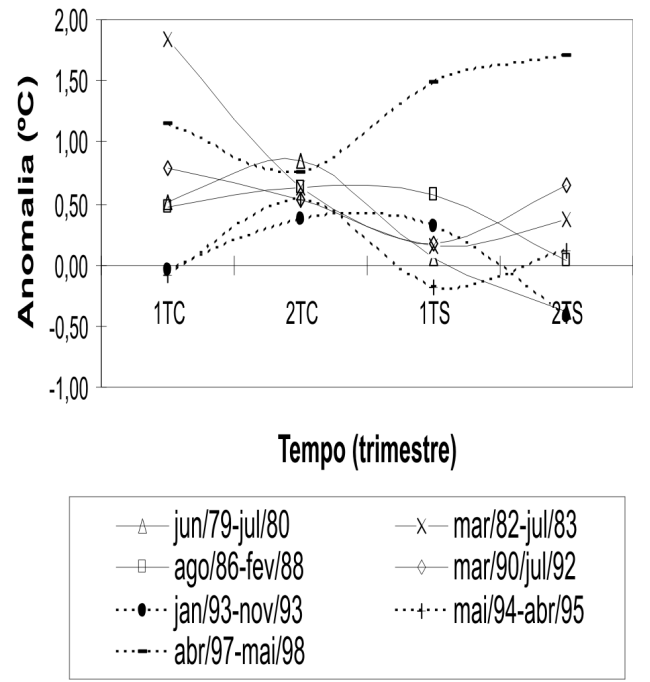

a - Eventos de El Niño

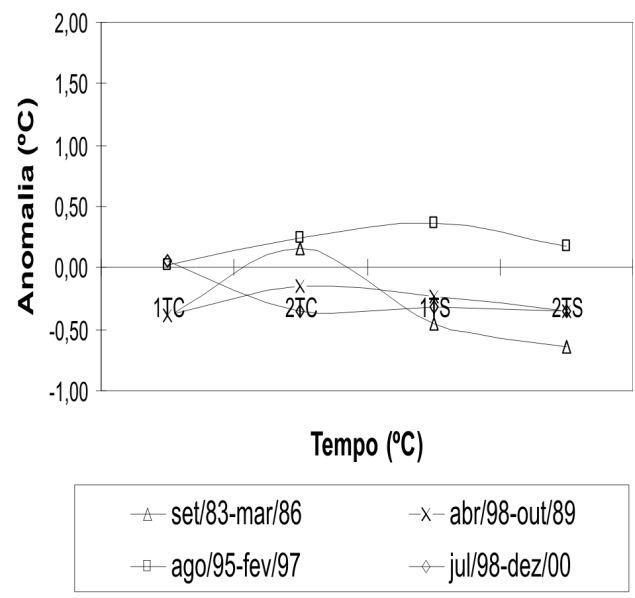

b - Eventos de la Ninã

Figura 14 - Anomalias de temperatura do ar de superfície em Manaus durante a fase positiva da ODP (1977-98).
ATS extremamente elevadas de até $1,84^{\circ} \mathrm{C}$ sobre o valor médio do período (Figura 14.a). Já, durante o episódio de 1997/98, as maiores ATS foram registradas durante o período normalmente mais seco e quente do ano e alcançou um valor médio de $1,71{ }^{\circ} \mathrm{C}$ no subgrupo $2 \mathrm{TS}$. Com isto, as temperaturas médias mensais do ar atingiram valores médios de $29,3{ }^{\circ} \mathrm{C}$ durante o segundo trimestre seco e de $30,2^{\circ} \mathrm{C}$ durante o mês de setembro de 1997.

Dessa forma, o aquecimento de $+0,27 \pm 0,04{ }^{\circ} \mathrm{C}$ nos últimos 80 anos não tem sido um fator constante ao longo da série. Na Figura 15, estão os resultados de uma análise observacional intrafases da ODP. Observa-se que as tendências expostas ratificam as observaçóes de Mantua et al (1997) e Molion (2004) nas informaçôes entre os modos, ou fases, da ODP e freqüências de meses com El Niño e/ou com La Niña.

$\mathrm{Na}$ Figura 15.b, observa-se tendências lineares negativas de $-0,23^{\circ} \mathrm{Ce}-0,33^{\circ} \mathrm{C}$ na seqüência das duas décadas internas à fase quente da ODP de 1925-46. Na Figura 12 é visível, nesse período, um grande número de meses neutros, com tendência a gerar ATS negativas, e uma quantidade significativa de eventos La Niña, com igual tendências negativa. Nesse período, notou-se que os eventos de El Niño foram aparentemente fracos, e não geraram aumentos significativos nos valores das
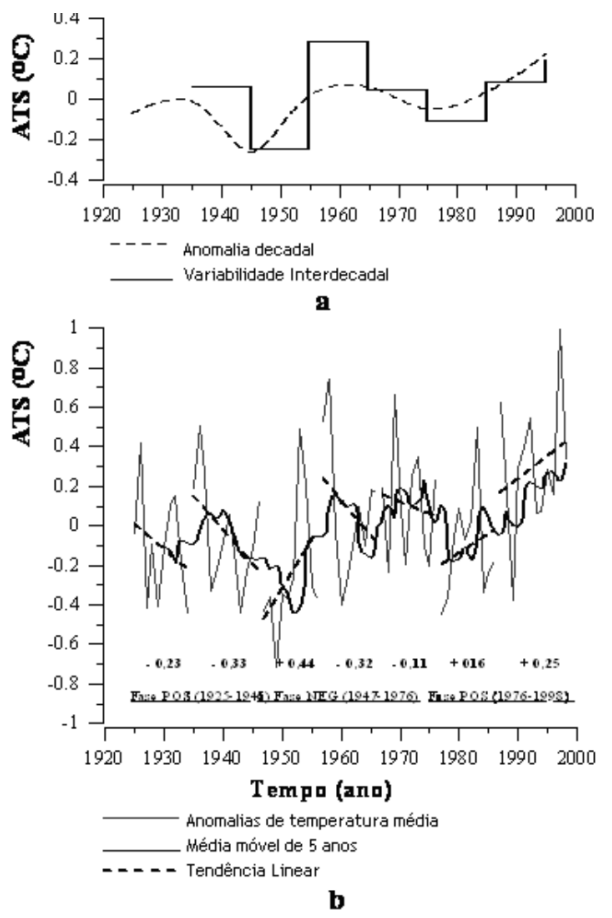

Figura 15 - Variabilidades e Tendências observadas da temperatura média do ar de superfície em Manaus entre 1921 a 2000. a - variabilidades interdecadais. b - variabilidades intrafases da ODP. 
temperaturas médias do ar, inclusive existindo trimestres com anomalias negativas.

A fase fria da ODP, de 1947 a 1976, apresentou um período com forte aquecimento de $+0,44^{\circ} \mathrm{C}$, ressaltando que outros mecanismos podem estar envolvidos. Contudo, notouse que, na década anterior, havia fortes anomalias negativas (Figura 15.a). Todavia, as duas décadas seguintes, foram de anomalias negativas, de $-0,32{ }^{\circ} \mathrm{Ce}-0,11^{\circ} \mathrm{C}$, respectivamente, as quais estão de acordo com a maior freqüência de La Niñas e meses neutros, conforme Oliveira (2006), que verificou que eventos neutros propiciaram um maior número de meses com desvios positivos de precipitação. Nesse sentido, poderia se diagnosticar uma tendência de anomalias negativas nas temperaturas médias do ar na região da cidade de Manaus para os próximos 20 ou 30 anos, caso se confirme um novo período de fase fria ODP. Contudo, ficou evidente que outros mecanismos podem estar envolvidos. Ainda na Figura 15.b, no período de 1976 a 1998 (fase quente da ODP), observaramse duas décadas com tendências de aquecimento de $+0,16$ ${ }^{\circ} \mathrm{C} \mathrm{e}+0,25^{\circ} \mathrm{C}$, respectivamente. $\mathrm{Na}$ segunda década, viu-se, novamente, a nítida influência dos fortes eventos de El Niño 1982-83 e 1997-98, considerados os de maior magnitude e de maior impacto econômico e social ao redor do globo no século passado.

A variabilidade interdecadal, apresentada na Figura 15.a, permitiu concluir que grande parte do incremento registrado na temperatura do ar em Manaus ocorreu em dois períodos, nas décadas de 1950 e a partir da década de 1980 com aquecimento acentuado durante a década de 1990, atribuídos aos fortes episódios de El Niño registrados neste período. Notar, que a década de 1950 não compõe uma fase fria da ODP, contudo, na tabela 5 de Oliveira (2006), verificou-se que os eventos de El Niño de 1953/54 e 1957/58 impulsionaram este aumento linear da temperatura média do ar, não explicado pela modo ODP. Isso não pode ainda ser considerado uma mudança climática, e, sim variabilidade climática, já que houve uma forte associação com as oscilações, das TSM do Oceano Pacífico, aparentemente naturais.

De um modo geral, as tendências verificadas neste trabalho comprovaram que os eventos de El Niño contribuíram, de forma significativa, com o aumento da temperatura média na cidade de Manaus e que os eventos de La Niña e meses neutros contribuíram para anomalias negativas da temperatura média do ar na cidade de Manaus.

Pelo acima exposto, verificamos haver boa concordância entre os valores de anomalias das TSM do Pacífico, na Região Niño 3.4, e padrões da ODP, com os valores de anomalias de temperatura do ar e precipitação pluviométrica na região de Manaus. É evidente que a Oscilação Decadal do Pacífico pode influenciar no comportamento do ENOS, mas não explica todo o conjunto do processo, por exemplo, o aumento linear das temperaturas evidenciado na década de 1950.

Assim, existe um entendimento real de que o comportamento das condições térmicas superficiais da bacia do Pacífico tem importância primária na variabilidade climática sobre os continentes, em específico, na cidade de Manaus.

\section{CONCLUSÕES}

Os resultados deste estudo mostraram que da variabilidade total da temperatura média do ar e do solo na cidade de Manaus, uma pequena fração deveu-se à influência da oscilação na freqüência de eventos do ENOS, mas que, contudo, outros mecanismos atmosféricos, como aqueles associados ao Oceano Atlântico tropical (Souza et al, 2000; Pezzi \& Cavalcanti, 2001) podem estar envolvidos (não mostrado aqui). Além disso, mostramos que o do uso do solo aumenta os valores da temperatura média superficial quase que instantaneamente (de modo abrupto). Desta forma, a fração local atribuída pelo uso do solo na variabilidade da temperatura média do ar foi inerentemente muito maior do que a fração atribuída pelos fenômenos naturais.

Observamos que os desvios da temperatura média do ar na cidade de Manaus modulados em parte pelas freqüências dos meses com El Niño, La Niña e neutros, apresentaram ao longo dos últimos 80 anos um incremento linear de $0,27 \pm 0,04^{\circ} \mathrm{C}$. Grande parte desse incremento ocorreu em dois períodos, na década 1950 pelos eventos do El Niño de 1953/54 e 1957/58, não explicados pela ODP, e posteriormente, a partir da década de 1980 acentuando-se durante a década de 1990, nos eventos do El Niño de 1991/94 e 1997/1998.

Em base na geotermia rasa, determinamos o valor atual da temperatura média anual da cidade de Manaus de 26,76 $\pm 0,10^{\circ} \mathrm{C}$, cujo valor está em conformidade com o valor obtido via observação instrumental de 26,65 $\pm 0,33^{\circ} \mathrm{C}$. Concluiu-se que, para as localidades que não possuem dados meteorológicos, o método geotérmico é bastante preciso na obtenção de valores climatológicos de temperatura média do ar.

As análises das perfilagens indicaram um incremento médio da temperatura média anual na cidade de Manaus de 3,17 $\pm 0,53{ }^{\circ} \mathrm{C}$, estimado desde a segunda metade do século XIX e modulado pela ocupação do homem na região, mediante a alteração do balanço energético da superfície pelo desmatamento e urbanização. Verificamos, também, que tais incrementos ocorreram de forma quase que instantânea na época.

Concluímos que, os perfis geotérmicos sob locais sem cobertura vegetal podem inferir com alto grau de detalhe as mudanças no microclima via as forçantes antrópicas. Também, 
verificamos que as perturbações transientes no regime térmico raso sob os locais com cobertura vegetal, podem ser usados como indicadores da variabilidade dentro do ciclo anual, as quais são detectadas igualmente em superfície pelas estações meteorológicas e sugerimos, como trabalhos futuros, experimentos geotérmicos de monitoramento contínuo das perturbações transientes.

\section{AGRADECIMENTOS}

Ao Instituto Nacional de Meteorologia por disponibilizar registros instrumentais de superfície e ao Laboratório de Geofísica do Departamento de Geociências do Instituto de Ciências Exatas da Universidade Federal do Amazonas que forneceu a infra-estrutura necessária para a execução do projeto.

\section{REFERÊNCIAS}

Aceituno, P. 1988. On the Functionning of the Southern Oscillation in the South America Sector - Part I: Surface Climate. Monthly Weather Review. 116 (3): 505-524.

Araujo, R.L.C.; Silva, R.M. 1982. Estimativas Preliminares de Gradiente Geotérmico Concernente à Cidade de Manaus. Anais do XXXII Congresso Brasileiro de Geologia, Salvador, setembro, 4: $16015-1620$.

Araujo, R.L.C.; Souza, J.R.S.; Makino, M. 1984. Análises de Perfis de Temperatura na Camada Intempérica da Área Metropolitana de Belém. Anais do XXXIII Congresso Brasileiro de Geologia, Rio de Janeiro, outubro, V.4, 2073-2083.

Araujo, R.L.C.; Makino, M.; Souza, J.R.S. 1985. Estudo da Variação Temporal de Perfis Geotérmicos na Camada Intempérica na Amazônia. Anais do II Simpósio de Geologia da Amazônia, Belém, dezembro, 3: 195-206.

Araujo, R. L. C. 1987. Geotermia Rasa em Belém. Tese de Doutourado. Universidade Federal do Pará (PA). 149pp.

Araujo, R.L.C.; Souza, J.R.S.; Makino, M. 1991. Análises dos Perfis Geotérmicos Rasos em Poços Sujeitos a Aquecimento Superficial e Bombeamento de Água. Revista Brasileira de Geofísica. 9: 47-53.

Araujo, R. L. C. 1999. Contribuição da Geotermia Rasa aos Estudos Ambientais. Manaus. Ed. Universidade do Amazonas. 88pp.

Astier, J.L. 1975. Geofísica Aplicada a la Hidrogeologia. Madrid, Parainfo. 344 pp.

Beck, A.E. 1965. Techniques of Measuring Heat Flow on Land. In: Lee, W., Terrestrial Heat Flow. Washington. American Geophysical Union. p. 24-57.

Beltrami, H. 2002. Climate from Borehole Data: Energy Fluxes and Temperatures Since 1500. Geophys Res Lett. 29(23): 2111, doi:10.1029/2002GL015702.

Bowen, R. 1966. Paleontemperature Analyses. Methods in Geochemistry and Geophysics. Elsevier. Publishing, 265pp.

Carslow, H. S.; Jaeger, J. C. 1959. Conduction of Heat in Solids. $2^{a}$ ed. Oxford. Clarendon Press. 527pp.
Ferguson, G.; Beltrami, H. 2005. Transient Lateral Heat Flow due to Land-Use Changes. Earth and Planetary Science Letters. 242(1-2): 217-222.

Gibbs, W. J.; Maher, J. V. 1967. Rainfall deciles as drought indicators. Bureau of Meteorology Bulletin.Commonwealth of Australia, Melbourne. 48.

IPCC. 2001. Climate Change 2001 - The Scientific Basis. Contribution of Working Group I to the Third Assessment Report of the IPCC. Published for the Intergovernmental Panel on Climate Change. New York: Cambridge University Press. 1-84.

JISAO. 2005. Join Institute for the Study of the Atmosphere and Ocean. (http://jisao.washington.edu/pdo/PDO.latest).

Kalnay, E.; Cai, M. 2003. Impact of Urbanization and Land-Use Change on Climate. Nature. 423: 528-531.

Kayano, M.T.; Moura, A.D. 1986. O El Niño de 1982-83 e a Precipitação sobre a América do Sul. Revista Brasileira de Geofisica. 4(2): 201-214.

Kousky, V.E.; Cavalcanti, I.F.A. 1984. Eventos Oscilação Sul / El Nino. Características, Evolução e Anomalias de Precipitação. Ciência e Cultura. 36(11): 1888-1899.

Lachenbruch, A.; Marshall, B.V. 1986. Changing Climate: Geothermal Evidence from Permafrost in the Alaska Artic. Sci. 234: 689-696.

Mantua, N.J.; Hare, S.R.; Zhang, Y.; Wallace, J.M.; Francis, R.C. 1997. A Pacific interdecadal climate oscillation with impacts on salmon production. Bulletin of the American Meteorological Society. 78: 1069-1079.

Molion, L.C.B. 2004. Aquecimento Global, Manchas Solares, El Niño e Oscilação Decadal do Pacífico.(http://geocities.yahoo. com.br/zuritageo/aquecimentoglobal.htm). Acesso: 08/2005.

Nitiou, D.; Beltrami, H. 2005. Subsurface Thermal Effects of Land Use Changes. Journal of Geophysical Research. 110, F01005, doi:10.1029/2004JF000151.

Oliveira, F.N.M. 2006. Inferência de Mudanças Microclimáticas na Regiāo de Manaus (AM) Usando dados Geotérmicos e Meteorológicos. Dissertação de Mestrado. Universidade Federal do Amazonas (AM). 138 pp.

Riehl, H.1965. Tropical Meteorology. First Edition. McGraw-Hill Book Company. 426 pp.

Roy, R. F.; Blackwell, D.D., Decker, E.R. 1971. Continental Heat Flow. In: Robertson, R. The Nature of Soil. New York: Mc GrawHill. p 506-543.

Serra, P.N. 2002. Determinação da Profundidade de Influência da Perturbação Térmica Sazonal Gerada pelo Aquecimento Solar na Região Metropolitana de Manaus. Universidade Federal do Amazonas. Dissertação de Mestrado. 80 pp.

Silva, R.M. 2003. Influência Ambiental sobre a Estrutura Geotermal Rasa. Dissertação de Mestrado. Universidade Federal do Amazonas (AM). 102 pp.

Souza, J.R.S.; Pinheiro, F.M.A.; Araujo, R.L.C.; Pinheiro, Jr.; H.S.; Hodnett, M.G. 1996. Temperature and Moisture Profiles in Soil Beneath Forest and Pasture Areas in Eastern Amazonia. Amazonian Deforestation and Climate. Capítulo 6. Editado por Gash, J.H.C., 
Nobre, C.A.; Roberts, J.M. \& Victoria, R.L. John Wiley \& Sons. England. p 125-137.

Souza, E., Kayano.; M. T., Tota, J.; Pezzi, L.; Fisch, G.; Nobre, C. (2000). On the influences of the el niño, la niña and atlantic dipole pattern on the amazonian rainfall during 1960-1998. ACTA Amazônica, 30(2): 305-318.

Souza, E.B.; Ambrizzi, T. 2002. ENSO Impacts on The South American Rainfall during 1980s: Hadley and Walker Circulations. Atmósfera. 15: 105-120.

Souza, E.B.; Kayano, M.T.; Ambrizzi, T. 2005. Intraseazonal and Submonthly Variability over the Eastern Amazon and Northeast Brazil during the Autumn Rainy Season. Theoretical and Applied Climatology. 81: p 177-191.

Trenbert, K, E. The Definition El Niño. 1997. Bulletin of the American Meteorological Society. 78: p. 2771-2777.

Trenbert, K. E.; Stepaniak, D.P. 2001. Indices of El Niño Evolution. J. Climate. 14: 1697-1701. 
